\title{
RECONHECIMENTO DO PARADOXO: O PROJETO DE PESQUISA DE MERLEAU-PONTY
}

\author{
Thiago Martins dos Santos Silva*
}

\begin{abstract}
Resumo
"Não é possível, nos limites de um artigo, justificar uma concepção de mundo" O que tentarei, ao contrário, é mostrar, brevemente, como conceitos específicos na obra de Merleau-Ponty se desenvolvem, a saber, os conceitos de corpo e de intercorporeidade. Tal abordagem não busca dar conta de todo o significado que estes conceitos teriam, mas antes onde se posicionam no gesto inicial de pesquisa empreendido por MerleauPonty: se "a literatura francesa está contida na língua francesa, ou as obras de um escritor em seu estilo", então é legítimo buscar o desenvolvimento ulterior de ideias que já estariam contidas no livro $O$ primado da percepção e suas consequências filosóficas, ao menos como contribuição para os estudos sobre Merleau-Ponty, onde seu crescente encaminhamento rumo a uma nova ontologia, estaria em estado latente em várias obras deste filósofo. Ora, problemas clássicos em filosofia, como a percepção das coisas, a unidade do múltiplo sensível, a relação com outras consciências, são consideradas por Merleau-Ponty como "contradições fecundas" originadas pelo primado da percepção. Tendo esta constatação da natureza paradoxal destas operações, buscaremos então, trilhar um caminho que vai dos estudos sobre o corpo objetivo da ciência até a intercorporeidade, procurando encontrar o ponto em que estas pesquisas fazem uma dobra e estaremos no limite de uma nova concepção de Ser.
\end{abstract}

\section{Introdução}

"Não é possível, nos limites de uma artigo, justificar uma concepção de mundo"1 O que tentarei, ao contrário, é mostrar, brevemente, como conceitos específicos na obra de Merleau-Ponty se desenvolvem, a saber, os conceitos de corpo e de intersubjetividade, principalmente na Fenomenologia da percepção. Tal abordagem não busca dar conta de todo o significado que estes conceitos teriam, mas antes onde se posicionam no gesto inicial de pesquisa empreendido por Merleau-Ponty: se "a literatura francesa está contida na língua francesa, ou as obras de um escritor em seu

\footnotetext{
* UFG, thiagomusique@gmail.com. Trabalho inédito.

${ }^{1}$ Merleau-Ponty, Maurice. Oevres. Paris: Guallimard, 2010; p 1332
} 
estilo"2, então é legítimo buscar o desenvolvimento ulterior de ideias que já estariam contidas no livro $O$ primado da percepção e suas consequências filosóficas, para ,ao menos, contribuir para os estudos sobre Merleau-Ponty, em seu crescente encaminhamento rumo a uma nova ontologia estaria em estado latente em várias obras deste filósofo.

Durante uma sessão da Sociedade Francesa de Filosofia, ao apresentar os resultados de sua pesquisa sobre a natureza da percepção, e ao apontar as possíveis consequências filosóficas desta última, Merleau-Ponty diz: "Assim como a percepção de uma coisa me abre ao ser, ao realizar a síntese paradoxal de uma infinidade de aspectos perceptivos, assim também a percepção de outrem funda a moralidade ao realizar o paradoxo de um alter ego"3. Neste trecho, o fenomenólogo francês, chama a atenção para a característica comum de duas operações distintas: a primeira dessas operações é a percepção das coisas, a segunda a percepção de outrem, e ambas seriam paradoxais. Estes paradoxos estão expressos, no mesmo trecho, como sendo a síntese das qualidades de uma coisa em uma unidade e o fundamento da moralidade pela posição de um outro eu.

Ora, estes problemas clássicos em filosofia, como a percepção das coisas, a unidade do múltiplo sensível, a relação com outras consciências, são consideradas por Merleau-Ponty como "contradições fecundas"4 originadas pelo primado da percepção. E esta contradição está no interior do próprio sujeito quando observado por outrem. Reconhece-se, portanto, o paradoxo e a contradição existentes na percepção de outrem.

Tendo esta constatação da natureza paradoxal destas duas operações, buscaremos, então, trilhar uma caminho que vai dos estudos sobre o corpo objetivo da ciência até a intercorporeidade, procurando encontrar o ponto em que estas pesquisas fazem uma dobra e estaremos no limite de uma nova concepção de Ser.

\section{0 corpo}

Ao tratar do corpo visto pela perspectiva fisiológica, na Fenomenologia da Percepção ${ }^{5}$, Merleau-Ponty decide apresentar o caso do membro invisível e a partir

\footnotetext{
${ }^{2}$ Op cit $\mathrm{p} 1526$

${ }^{3}$ Merleau-Ponty, Maurice. Le primat de la perception, Paris: Verdier 1996; p70

${ }^{4}$ Op cit; $p, 70$

${ }^{5}$ Oevres, p. 751 ; Merleau-Ponty, Fenomenologia da Percepção, São Paulo: Martins Fontes, 2011. P; 111
} 
deste caso, evidenciar os limites da abordagem científica que vê o corpo como uma coisa dentre outras. Trata-se de saber o que significa o membro invisível.

O membro invisível é um caso bastante conhecido e documentado. Durante guerras, por exemplo, alguns soldados, quando tem um membro amputado, ainda assim o sentem. Mesmo se anestesiados, certos mutilados permanecem com a sensação. E há casos mesmo, em que não houve nenhuma amputação real. A primeira resposta dada a este fenômeno, é psicológica: "Uma emoção, uma circunstância que relembre as do ferimento fazem aparecer um membro fantasma em pacientes que não o tinham"6, porém, acrescenta Merleau-Ponty: “ ocorre que o membro fantasma [...] se encolhe [..] "com o consentimento do doente em aceitar sua mutilação",7

“Seria preciso então dizer que o membro fantasma é uma recordação [...] e na falta de uma explicação fisiológica, dar uma psicológica?" 8 Merleau-Ponty quer mostrar que a abordagem, sempre dualista, em que se opõem fisiológico e psicológico, não dá conta deste caso. Uma simples explicação psicológica estaria excluída, porque "a secção dos condutores sensitivos que vão para o encéfalo suprime o membro fantasma." 9 Isto quer dizer que o membro fantasma é, também, um fenômeno fisiológico. Então, como explicar o membro fantasma?

Primeiramente, deixando de lado as divisões que fazem do fisiológico um em-si e do psicológico um para-si, isto é, instâncias distintas que não saberíamos reunir. Merleau-Ponty diz:

Ele [ o membro fantasma] só poderia ser uma mistura dos dois se encontrássemos o meio de articular um ao outro, o 'psíquico' e o 'fisiológico', o 'para si' e o 'em-si' e de preparar entre eles um encontro, se os processos em terceira pessoa e os atos pessoais pudessem ser integrados em um meio que lhes fosse comum" 10

Em seguida, Merleau-Ponty apresenta uma resolução: o membro fantasma é uma forma de recalque orgânico. E esta já é uma entrada para o tema do ser-no-mundo, outra ideia do corpo que não opera com estas divisões.

\section{O ser no mundo}

\footnotetext{
${ }^{6}$ Op cit 115

${ }^{7} \mathrm{p} ; 115$

8 P;116

${ }^{9} P ; 116$

${ }^{10} \mathrm{P} ; 116-117$
} 
A principal característica do ser-no-mundo é sua pré-objetividade. Isto quer dizer que na percepção não é posto um objeto de conhecimento, antes, temos aqui uma intenção de nosso ser total. Se pensarmos nosso corpo como uma esfera, por exemplo, os reflexos, atos que realizamos aparentemente sem pensar, estariam na periferia dessa esfera, mobilizando, portanto, pouco da nossa atenção; já na percepção mobilizo toda essa esfera, e isto significa que todo o meu ser está nesta intenção.

Merleau-Ponty diz:

"É por ser uma visão pré-objetiva que o ser no mundo pode distinguirse de todo processo em terceira pessoa, de toda modalidade da res extensa, assim como de toda cogitatio, de todo conhecimento em primeira pessoa - e que ele poderá realizar a junção do "psíquico" e do "fisiológico."

Em seguida Merleau-Ponty dá uma chave para a compreensão do problema do membro fantasma: "o corpo é um passado específico" 11 . Toda a questão era a de saber como explicar essa aparição. Anteriormente, havia surgido a ideia de um recalque orgânico, é disto que Merleau-Ponty chama o membro fantasma. Sua resolução passa por considerar três aspectos: primeiro, o corpo como passado nos permite entender a aparição do membro não como memória, simplesmente, ao menos no sentido psicológico, e muito menos como representação, pois na verdade ele é um "quasepresente" 12 ou melhor "presença ambivalente de uma braço" ${ }^{13}$; segundo, porque ao pensá-lo como recalque, isto é um passado que reluta em tornar-se presente, não aceita ser passado ( e ter passado), podemos unir esta ideia à anterior, e dizer que o corpo, este braço etc. pelo próprio esquema corporal, é um passado que se quer sempre presente. $\mathrm{E}$ por fim, assim como no recalque psicanalítico, ou no luto, é preciso que se aceite a perda do braço ou do ente querido, para curar-se.

Resolvido o problema do membro fantasma, estas colocações, excedendo o caso específico, tornam possível questionar se os resultados não podem ser ampliados. É o que Merleau-Ponty fará, ao por este ser no mundo em um mundo: veremos quais serão os resultados.

\section{Intersubjetividade}

\footnotetext{
${ }^{11}$ P. 162

$12 \mathrm{P}, 127$

${ }^{13}$ P121
} 
Anterior à Fenomenologia da percepção, A estrutura do comportamento ${ }^{14}$, livro no qual Merleau-Ponty estuda as relações entre as observações biológicas e psicológicas do comportamento, a configuração das formas, gelstaten, a relação entre a alma e o corpo etc., fornece para reflexões posteriores importantes resultados no pensamento de Merleau-Ponty. O principal deles, é claro, é elucidar como se estruturam os comportamentos, e qual o papel destes no todo perceptivo. Ora, anteriormente vimos como a ideia de ser no mundo nos havia ajudado a compreender o fenômeno do membro invisível, no entanto, apenas para nos laçar à questões maiores.

Se por um lado o ser no mundo é uma presença pré-objetiva, e portanto présubjetiva também, o qual tem acesso através da percepção e dos sentidos ao mundo físico, por outro o comportamento sedimenta-se neste mundo físico e transforma-o em mundo humano ou cultural. Diz Merleau-Ponty:

Não tenho apenas um mundo físico, não vivo somente no ambiente da terra, do ar e da água, tenho em torno de mim estradas, plantações, povoados, ruas, igrejas, utensílios, uma sineta, uma colher, um cachimbo. Cada um desses objetos traz implicitamente a marca da ação humana à qual ele serve. Cada um emite uma atmosfera de humanidade $(\ldots)^{15}$

Assim como o corpo desenvolve uma generalidade em torno de si, MerleauPonty atribui aos objetos do mundo humano o mesmo: cada um desses objetos aponta para uma presença humana. Não somente aponta, mas é o meio pelo qual dois sujeitos, de início, podem perceber-se: ao observar o comportamento de outrem em relação a objetos familiares de meu entorno, tenho o pressentimento de que este outrem pode ser um outro eu, uma outra consciência. O primeiro desses objetos culturais, para MerleauPonty, é "o corpo de outrem enquanto portador de um comportamento". ${ }^{16}$

Vive-se, no entanto, ainda em um mundo mudo. É preciso que apareça um outro objeto cultural: a linguagem. Esta abordagem de Merleau-Ponty quanto a linguagem vai ser retrabalhada posteriormente em sua obra póstuma $A$ prosa do mundo ${ }^{17}$, que possui um capítulo sobre o diálogo e a percepção do outro. Neste capítulo, reaparecem várias consequências descobertas na Fenomenologia: por exemplo, no diálogo,

\footnotetext{
${ }^{14}$ Merleau-Ponty, A estrutura do comportamento. São Paulo: Martins fontes, 2006

${ }^{15}$ Fenomenologia, p. 465

${ }^{16}$ Op. cit. p. 467

${ }^{17}$ Merlau-ponty, A prosa do mundo. São Paulo: Cosac Naify, 2012
} 
Constitui-se um terreno comum entre outrem e mim, meu pensamento e o seu formam um só tecido, meus ditos e aqueles do interlocutor são reclamados pelo estado da discussão, eles se inserem em uma operação comum da qual nenhum de nós é o criador ${ }^{18}$

Merleau-Ponty observa que possuímos em nossa língua um pronome indefinido: se. Este pronome refere-se a uma espécie de eu em geral, que compartilha da mesma generalidade do corpo. Um Eu que posso atribuir à outros. Entretanto, Merleau-Ponty não se satisfaz com estes apontamentos, pelo contrário vai mais longe ao dizer: " a generalidade do corpo não fará compreender como o Eu indeclinável pode alienar-se em benefício de outrem". Isto é, a aparentemente irrecusável atitude reificadora da minha consciência em relação a outras, faz duvidar se é realmente possível esta simultaneidade de consciências, este apagamento do eu e do tu em um nós, este otimismo no agir comunicativo.

Mas é por outro caminho que vai Merleau-Ponty: o diálogo não é um "ver em Deus" ${ }^{19}$, ou seja, posicionar-me nesta neutralidade entre um sujeito e outro; como afirma Merleau-Ponty: "por mais que nossas consciências,(...), construam um situação comum na qual elas se comuniquem, é a partir do fundo de sua subjetividade que cada um projeta este mundo "único". ${ }^{20}$ Mas então, como é possível uma relação não reificante, não impessoal, entre as consciências? Merleau-Ponty propõe:

Meu olhar só transforma [o outro] em objeto se nós dois nos retirarmos para o fundo de nossa natureza pensante, se nós nos olharmos de modo inumano, se cada um sente suas ações, não retomadas e compreendidas, mas observadas como as ações de um inseto.

Isto implica, também, compreender a consciência não como uma "consciência constituinte e como um puro ser para si, mas como uma consciência perceptiva, como o sujeito de um comportamento, como ser no mundo ou existência."

\section{Conclusão}

Por todo este trabalho, ao passarmos muito rapidamente por conceitos e problemas merleau-pontianos, com frequência foi dito que se deve superar um

\footnotetext{
18 p. 474

19 P.480

${ }^{20}$ p. 478
} 
pensamento baseados em separações como ser em si e ser para si. Merleau-Ponty chega mesmo a dizer que o corpo na cultura é um ser para nós. Mas é para outro conceito que ele se dirige, onde crê que está uma solução.

Durante as discussões sobre o diálogo, seus limites, Merleau-Ponty afirmou que "entre o ser puro e o objeto, um terceiro gênero de ser." As divisões não são mais satisfatórias. Impedem a comunicação entre os homens, impede mesmo que se compreenda a relação destes com a economia, com sua sociedade, com sua nação, com sua classe. Todas estas são "modos de coexistência que o solicitam". Que durante períodos calmos são como estímulos, aos quais responde-se de modo distraído ou rotineiros, mas que durante momentos revolucionários "o engajamento tácito se torna explícito". ${ }^{21}$ São comportamentos que não são "fatalidades que submetam o indivíduo do exterior" ${ }^{\prime 22}$. Além destas várias consequências se podem retirar. Inclusive o passo ontológico para um Ser indiviso, Ser bruto que é uma separação do ser em si e do ser para si. ${ }^{23}$ Neste pequeno texto não será possível estudar este novo Ser, pois seria demasiado difícil em tão pouco espaço, mas fica apontado, ao menos, o caminho seguido por Merleau-Ponty.

Terminaremos, entretanto, com as palavras de Merleau-Ponty no final do capítulo da Fenomenologia dedicado ao outrem e o mundo:

No plano do ser, nunca se compreenderá que o sujeito seja ao mesmo tempo naturante e naturado, infinito e finito. Mas se sob o sujeito nós reencontramos o tempo, e se ao paradoxo do tempo correlacionarmos os do corpo, do mundo, da coisa e de outrem, compreenderemos que para além nada há a compreender. ${ }^{24}$

\section{Referências bibliográficas}

Chaui, Marilena. Experiência do pensamento. São Paulo: Martins Fontes, 2002

Merlau-Ponty, Maurice. A estrutura do comportamento. São Paulo: Martins fontes, 2006

\footnotetext{
${ }^{21}$ P. 487

22 P. 487

${ }^{23}$ Chaui, Marilena. Experiencia do pensamento. São Paulo: Martis Fontes, 2002. P. 156

${ }^{24}$ Fenomonologia, p. 490
} 
Paulo, 2011

Fenomenologia da percepção. São Paulo: São

. Oevres. Paris: Gallimard, 2010

. Le Primat de la perception. Paris : Verdier, 1996

. A prosa do mundo. São Paulo: Cosac Naify, 2012 